\title{
Study on the effect of some parameters of soil nails on the stability of vertical slopes
}

\author{
Nhan Thi Pham 1, ${ }^{*}$, Pan Bing ${ }^{2}$, Nghia Viet Nguyen ${ }^{3}$ \\ ${ }^{1}$ Faculty of Civil Engineering, Hanoi University of Mining and Geology, Vietnam \\ ${ }^{2}$ Power China Huadong Engineering Corporation Limited, Hangzhou, Zhejiang, China \\ ${ }^{3}$ Faculty of Geomatics and Land Administration, Hanoi University of Mining and Geology, Vietnam
}

\begin{abstract}
ARTICLE INFO
ABSTRACT

Article history:

Received $11^{\text {st }}$ Oct. 2020

Revised 28 $8^{\text {th }}$ Nov. 2020

Accepted 31 st Dec. 2020

Keywords:

Displacement,

Factor of safety,

Material models,

Nail length Pattern s,

Soil nailing inclinations.

Soil nailing is one of the soil reinforcement techniques that has been used worldwide in geotechnical engineering. In Viet Nam, soil nailing technology applied in a number of transportation investments such as $\mathrm{Ha}$ Long - Van Don, Bac Giang - Lang Son highways, and some of the hydropower plants in the central provinces of Viet Nam. Soil nailing is a system consisting of reinforced concrete piles and rebars or composite rods installed in an inclined direction into the slope. The research and applications of soil nailing technology to reinforceslopes in Viet Nam have not been widespread. The authors only considered construction technologies, processes, requirements for the materials, equipment, quality - check of soil nails, etc. The optimal geometries of soil nails for the stability of slope are inadequate and analyzed thoroughly. These lead to inaccurate prediction of the construction stabilization effect and the safety of designed structures. In the present study, numerical simulations were conducted to investigate the effects of the inclined angle and the length of soil nail Patterns and subjected to surcharge loads on stability improvement of soil - nailed slopes and facing deformation in a staged excavation. The research results show that the soil nail reinforcement efficiency could be affected by inclinations and length Pattern $s$ of soil nails. The general conclusion is that the more soil is nailing inclinations, the more the reinforcing forces in the soil nails. The soil nail length Patterns have also influenced displacement characteristics of slopes.
\end{abstract}

${ }^{*}$ Corresponding author

E- mail: phamthinhan@humg.edu.vn

DOI: 10.46326/JMES.2020.61(6).04

\section{Introduction}

The behavior of soil - nailed slopes is significantly affected due to various factors such as the installation method, construction sequence, soil and nails parameters, etc. To provide global stability, the soil nail should exceed the potential 
shear plane (Aitsev et al., 1991; Singh, and Babu, 2009; Geotechnical, 2008). The behavior of soil nail parameters, including both, the extent and magnitude of deflection, were adequately obtained and predicted using the 3D finite element method (Zhang et al., 1999). It was observed that as the nail length increased both the horizontal deflection and vertical settlement decreased. A series of centrifuge model tests were carried out on soil - nailed slopes subjected to seepage. It was also observed that the stabilizing effect decreases: (i) with rising water surface within the slope, (ii) increase in vertical and horizontal spacing of nails, and (iii) decrease in nail length (Tei et al., 1998; Deepa et al., 2009; Rotte et al., 2013; Moniuddin et al., 2016). On the other hand, they also concluded that all the slopes collapsed due to the nails' insufficient anchorage length beyond the failure plane. However, these research results were presented only for slopes, but not for vertical walls or without surcharge load.

For shorter length and denser spacing, external failure was noticed to occur. For more considerable length and sparser spacing (Zhang et al., 2001) observed internal failure. Many researchers have carried out different laboratory tests to study the effect of soil nail inclination on strengthening the soil. A review of the previous studies by Fan and Luo, (2008); Jewell and Wroth, (1987); Shiu and Chang, (2005); Nadher and Baghdadi, (2013); Shiu and Chang, (2005) have been conducted where the results are widely presented. A significant finding of these studies is that the overall shearing strength of reinforced soil is dependent on the orientations of reinforcement. The studies' most significant goal is zoning and forecasting, and therefore, a variety of proper and contemporary study methods is needed (Ha Viet Nhu et al., 2019).

The research and applications of soil nailing technology for reinforcement slopesare limited in Viet Nam. Up to the present, most authors have only pointed out the construction technology, processes, and requirements for materials and equipment, checking the quality after construction, etc. (Hanh Kim Dong, 2015).

A series of parametric studies via numerical analysis have been conducted to examine the effect of nail inclination and nail length Patterns on the development of soil stability improvement nailed slopes and facing deformation in a staged excavation. It is strongly believed that the results can contribute to the analyses and designs of such improvement methods in the future in the domestic construction industry.

\section{Material and methods}

\subsection{Soil and soil nail parameters}

The reinforcing action of soil nails can be developed through soil/nail interaction due to ground deformation, which results in the development of tensile forces in soil nails. This developed tension force is the central part of resistances. Conventionally, shear, and bending strength have been assumed to provide a little contribution to its resistance (Lazarte et al., 2015). The effect of soil nailing is to improve the stability of the slope through (1) increasing the normal force on the shear plane and increase the shear resistance along the slip plane in granular soils; and (2) reducing the driving force along the slip plane both in granular and cohesive soil. To illustrate and better understanding, a typical $6 \mathrm{~m}$ high soil - nailed wall with vertical face and horizontal backfill is considered for the present study (Figure 1).

The surcharge applied is caused by a vehicle load. Each vehicle weighs $(G)$ is 15 tons on average. The maximum number of vehicles that can be arranged on the road pavement's width is two vehicles. So the surcharge load per unit area $q$ $=n \times G=2 \times 15(t)=30 \mathrm{t} / 30 \mathrm{~m}^{2}=1\left(\mathrm{t} / \mathrm{m}^{2}\right)=10$ $\left(\mathrm{kN} / \mathrm{m}^{2}\right)$. If two is considered the Factor of Safety, the surcharge load per unit area is $20\left(\mathrm{kN} / \mathrm{m}^{2}\right)$.

Table 1 summarises the geometric configuration and other design details of the soil nail wall. PLAXIS 8.6 was used to carry out the finite element based simulations of the soil nail wall, considering it as a plane strain problem and accounting for the long term behavior using drained conditions.

Numerical simulations of the soil nail wall are performed considering the Mohr Coulomb (MC) model. The observations are made regarding global stability, displacements of the excavation base, lateral deformations, and axial forces in the nails after each construction stage. 

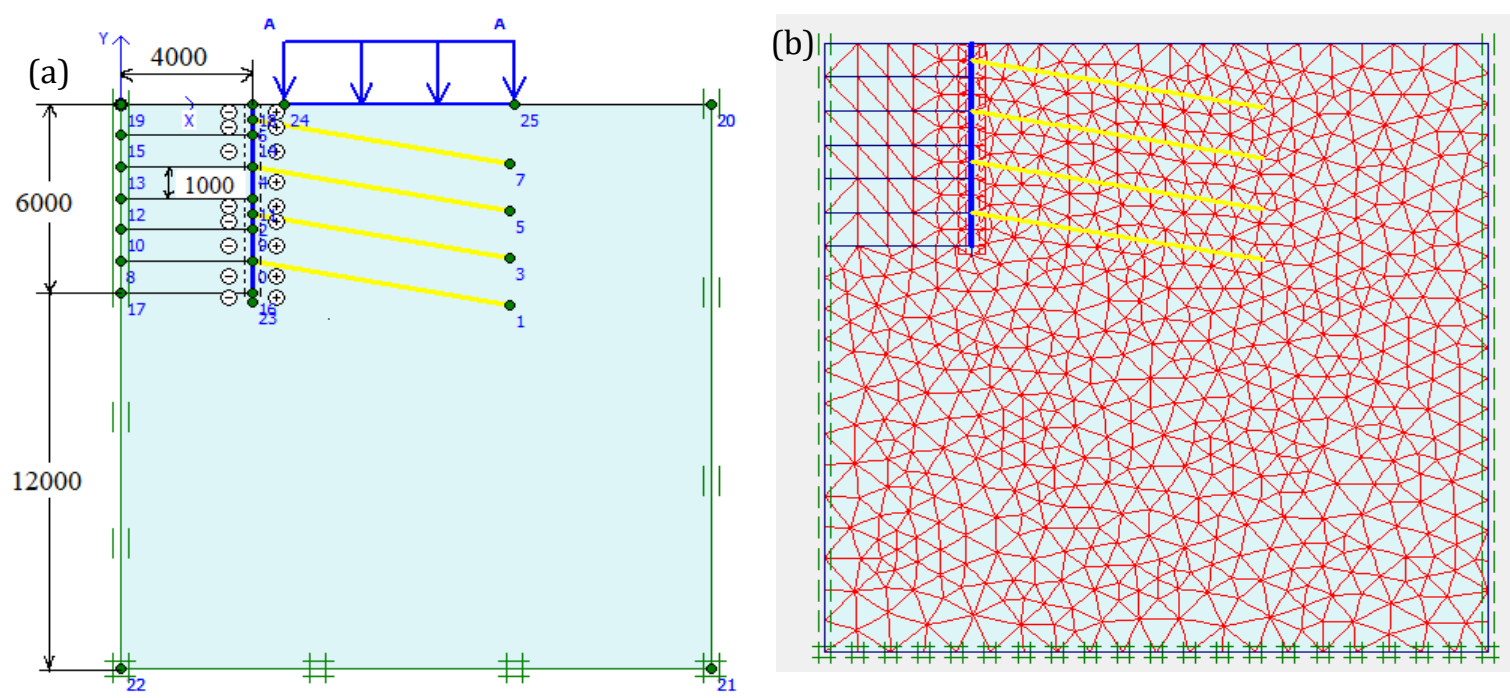

Figure 1. Numerically simulated $6 \mathrm{~m}$ high soil - nailed slope.

(a) Geometry of model slope; (b) Model after meshing in 2D.

Table 1. Soil geotechnical parameters.

\begin{tabular}{|c|c|c|c|c|}
\hline $\mathrm{N}_{\mathrm{o}}$ & Parameters & Name & Unit & Material model Mohr - coulomb \\
\hline 1 & Cohesion & $C$ & $\mathrm{kPa}$ & 10 \\
\hline 2 & Unit weight & $\gamma_{\text {sat }}$ & $\mathrm{kN} / \mathrm{m}^{3}$ & 19 \\
\hline 3 & Internal friction angle & & $\circ$ & 40 \\
\hline 4 & Poison's ratio of soil & & - & 0,3 \\
\hline 5 & Dilatancy angle & $\Psi$ & & 0 \\
\hline 6 & Elastic modulus & $E$ & $\mathrm{kN} / \mathrm{m}^{2}$ & 30000 \\
\hline
\end{tabular}

Table 2. Facing and soil nail parameters.

\begin{tabular}{|c|c|c|c|c|}
\hline $\mathrm{N}_{\mathrm{o}}$ & Material type & \multicolumn{2}{|c|}{ Geogrid } & Elastic \\
\hline 1 & Normal stiffness & $E A$ & $1.06 \mathrm{E}+06$ & $\mathrm{kN} / \mathrm{m}$ \\
\hline 2 & Length & $L$ & 8 & $\mathrm{~m}$ \\
\hline 3 & Nail inclination & $\alpha$ & $0,10,20,30,40$ & 0 \\
\hline \multicolumn{4}{|c|}{ Grouted nails and facing } \\
\hline 1 & Normal stiffness & $E A$ & $2.2 \mathrm{E}+06$ & $\mathrm{kN} / \mathrm{m}$ \\
\hline 2 & Bending stiffness & $E I$ & $1.84 \mathrm{E}+03$ & $\mathrm{~m} \mathrm{~m}^{2} / \mathrm{m}$ \\
\hline 3 & Facing thickness & $d$ & 0.15 & 0.25 \\
\hline 4 & Poisson's ratio & & &
\end{tabular}

Below is the short description of multiple necessary parameters in the MC model, which was used to simulate the soil nail wall. The study's primary objective isto bring out the implications of the use of soil models. Typical values of the different soil model parameters used in the study are summarised in Tables 1 and 2 .

The following three nail length patterns were carried out to review the effect of different nail length patterns on the deformation of excavations (Figure 2): depth

Pattern (1) - nail length decreasing with

Pattern (2) - constant nail length;

Pattern (3) - nail length increasing with depth.

As mentioned earlier, soil nail walls are simulated as a plane strain problem and long term behaviour is simulated using drained analysis conditions. 15 - noded triangular elements are used to generate finite element mesh of appropriate density. Coarse mesh density 
is adopted globally, which is refined to fine density in the vicinity of the soil nail wall (Figure 1). Mesh boundaries are placed far enough to minimize the influence of mesh boundaries on the numerical simulation results (Briaud and Lim, 1997). Figures 1 and 2 showed the simulated soil nail wall with excavation and soil nail dimensions and various parameters, including in situ soil properties, mesh boundaries, and fixity conditions.

\subsection{Calculation of axial stiffness (EA) and bending stiffness (EI)}

The axial stiffness $E A$ and the flexural rigidity (bending stiffness) $E I$ are the most critical input material parameter for the structural elements simulating soil nails. Most commonly, plate structural elements and geogrid structural elements (which only require the axial stiffness $E A$ as input) are being used to simulate soil nails. The shapes of the plate and geogrid structural elements are usually rectangular with the width equalling to $1 \mathrm{~m}$ in out - of - plane direction (Rotte et al., 2013). However, the soil nails are placed at designed horizontal spacing and circular in cross - section. It is necessary to determine equivalent axial and bending stiffness for the correct simulation of circular soil nails as rectangular plate structural elements.

For the grouted nails, the contribution of elastic stiffness of both grout cover as well as reinforcement bar should be determined based on the modulus of elasticity $\left(E_{e q}\right)$ (Jones and Davies, 2000). From the fundamentals of the strength of materials, $E_{e q}$ can be determined as:

$$
E_{e q}=E_{n}\left(\frac{A_{n}}{A}\right)+E_{g}\left(\frac{A_{g}}{A}\right)
$$

Where: $E_{e q}$ - The equivalent modulus of elasticity of grouted soil nail; $E_{n}$ - The modulus of elasticity of nail; $E_{g}$ - The modulus of elasticity of grout material; $A$ - The total cross - sectional area of grouted soil nail, $A=0.25 \pi D_{D H}^{2} ; \mathrm{D}_{\mathrm{DH}}$ - The diameter of drill hole; $A_{g}$ - The cross - sectional area of grout cover, $A_{g}=A-A_{n} ;\left(A_{n}\right)$ - The cross sectional area of reinforcement bar, $A_{n}=$ $0.25 \pi d^{2} ; d$ - The diameter of drill hole.

If $S_{h}$ is horizontal spacing of soil nails, knowing the equivalent modulus of elasticity $\left(E_{\text {eq }}\right)$. Equation (1) for the grouted soil nail, the
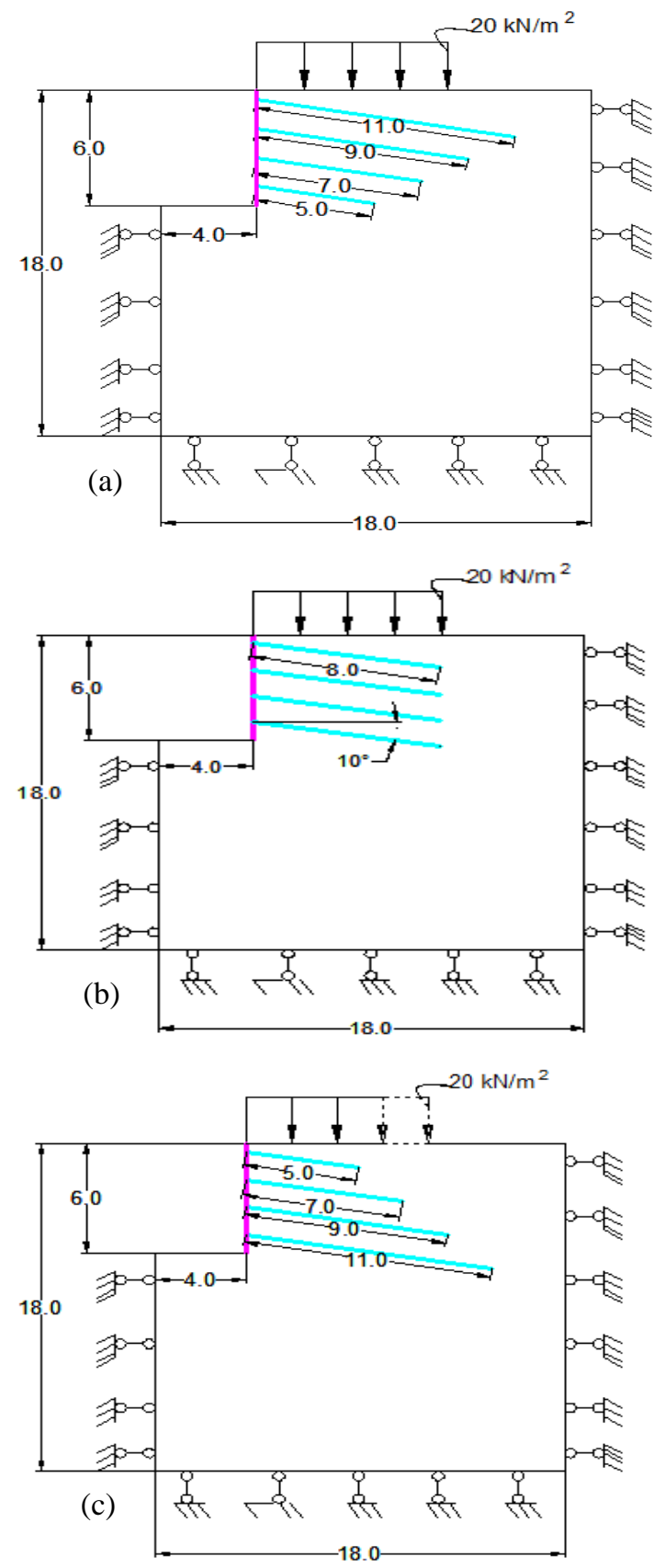

Figure 2. Three nail length Patterns.

a) Pattern (1); b) Pattern (2); c) Pattern (3).

bending, and axial stiffness can be determined using Equations (2) and (3), respectively

$$
\begin{gathered}
E I=\frac{E_{e q}}{S_{h}}\left(\frac{\pi D_{D H}^{4}}{64}\right),\left[\frac{k N m^{2}}{m}\right] \\
E A=\frac{E_{e q}}{S_{h}}\left(\frac{\pi D_{D H}^{2}}{4}\right),\left[\frac{k N}{m}\right]
\end{gathered}
$$




\subsection{General Procedure for Numerical Simulation}

The general steps in the numerical simulation of the soil nail wall are listed below:

Firstly, material properties, geometry of the soil nail wall (including nails and facing elements layout), boundary conditions are defined in the input program.

- Secondly, desired mesh density was chosen. This is followed by initial gravity stresses using $\left(k_{0}\right)$ procedure (i.e. at - rest condition).

- Thirdly, staged construction option was used to simulate the construction of the soil nail wall in ten stages indicated below:

Stage 1: Excavating and removing the first layer of soil to the depth of - $1.0 \mathrm{~m}$, activating surcharge load of $20 \mathrm{kN} / \mathrm{m}^{2}$;

Stage 2: Installing the first row of soil nail to the depth of $-0.5 \mathrm{~m}$

Stage 3: Excavating and removing the second layer of soil to the depth of $-2.0 \mathrm{~m}$

Stage 4: Installing the second row of soil nail to the depth of - $2.0 \mathrm{~m}$

Stage 5: Excavating and removing the second layer of soil to the depth of $-3.0 \mathrm{~m}$

Stage 6: Excavating and removing the second layer of soil to the depth of $-4.0 \mathrm{~m}$

Stage 7: Installating the third row of soil nail to the depth of $-3.5 \mathrm{~m}$

Stage 8: Excavating and removing the second layer of soil to the depth of $-5.0 \mathrm{~m}$

Stage 9: Installing the second row of soil nail to the depth of - $5.0 \mathrm{~m}$

Stage 10: Excavating and removing the second layer of soil to the depth of $-6.0 \mathrm{~m}$

\section{Result and discussion}

By using Plaxis software, the results of stability analysis of soil - nailed slopes were modeled and presented with special attention paid to the factors influencing the stability of soil nailed slopes. In the simulation, the inclined angle of nails and nail length Pattern are the factors that were investigated.

\subsection{Effect of the inclined angle of nails}

Based on the reduced $\mathrm{c}$ and $\phi$ parameters of the soil, the factor of safety (FOS) in the currently used model can be computed according to
Equation (4), proposed in the calculation window of PLAXIS. While calculating FOS using the finite element - strength reduction method, the entire slope, from toe to the crest, was in the range that involves all elements in a plastic state. The principal described above is the principal definition for $\phi-c$ reduction method, which was used here to compute the global factor of safety.

$$
F O S=\frac{C-\sigma_{n} \tan \phi}{C_{r}-\sigma_{n} \tan \phi_{r}}
$$

Where: $\sigma_{n}$ is the acting normal stress component; $c$ and $\phi$ are input soil strength parameters; $C_{r}$ and $\phi_{r}$ are reduced strength parameters, large enough to maintain equilibrium.

In this approach, the tangents of internal friction angle and the cohesion are reduced in the same proportion:

$$
\frac{C}{C_{r}}=\frac{\tan \phi}{\tan \phi_{r}}=\sum M s f
$$

In which the total multiplier $\left(\sum M s f\right)$ control the reduction of those parameters. The total multiplier will be increased in a step by step procedure until the failure occurs. So, the value of $\sum M s f$ at the failure phase is defined as the factor of safety (FOS).

In this report, construction progressed incrementally in a top down manner by repeating two steps of construction. The first step began with soil being excavated to a depth of $0,5 \mathrm{~m}$ below the soil nail level. Step 2 consisted of installing the soil nail and concrete facing. Steps 1 and 2 were repeated until the full excavation depth (6 m) was attained. The inclined angle $(\alpha)$ is the angle of a soil nail, regarding horizontal direction. The effects of $\alpha$ were studied by changing the $\alpha$ within a range of $0^{0}$ and $25^{\circ}$. The typical relationship between $\alpha$ and calculated FOS is presented in Figure 3.

The FOS is close to 1,5 with little variations for the range of $\alpha$ between $0^{0}$ and 20 $0^{\circ}$. The FOS decreases substantially as $\alpha$ increases beyond $20^{\circ}$, reflecting that the reinforcing action of the nails reduces rapidly with increasing nail inclinations. When $\alpha$ equals to $25^{0}$, the FOS is close to 0 . This indicates that soil nails (modeled as geogrid) at such large inclinations do not provide any appreciable stabilizing effect. 
The total of the maximum tensile forces in all the soil nails $\left(\Sigma T_{\max }\right)$ at limit equilibrium condition of the model are given in Table 3 . This Table shows the value of the maximum nail forces $\left(\Sigma T_{\max }\right)$ when $\alpha$ varies from $0 \div 20^{0}$.

Table 3. The total of the maximum tensile forces of all the soil nails.

\begin{tabular}{|c|c|c|}
\hline No & $\begin{array}{c}\text { The inclination } \\
\text { of soil nails, } \alpha \\
(0)\end{array}$ & $\begin{array}{c}\text { Total of maximum nail } \\
\text { tensile forces, } \Sigma t_{\text {max }} \\
(\mathrm{kN} / \mathrm{m})\end{array}$ \\
\hline 1 & $0^{0}$ & 964 \\
\hline 2 & $5^{0}$ & 945 \\
\hline 3 & $10^{0}$ & 991 \\
\hline 4 & $15^{0}$ & 978 \\
\hline 5 & $20^{0}$ & 840 \\
\hline
\end{tabular}

The above result shows that FOS related to $\Sigma T_{\max }, F O S$ tends to be zero when $\Sigma T_{\max }$ is close to zero. In comparison, $\Sigma T_{\max }$ decreases with increasing $\alpha$.

As reported above, the nail inclinations certainly affected the distribution and magnitude of the axial forces. The distributions of displacements of slope face with the different nailed soil inclination from $\alpha=0 \div 20^{0}$ are given in Figure 4.

Figure 4 illustrates the profiles of horizontal deformation of the slope face as a function of nail inclinations at the final stage of excavation. The horizontal deformation increases with increasing nail inclinations, and there is a sharp increase in deformations when the excavation depth increases from $2 \div 6 \mathrm{~m}$. The analytical results also show that the horizontal displacement magnitude is influenced by the soil nail inclination.

\subsection{Effect of nail length Pattern}

The effect of different nail length Pattern son the factor of safety was carried out on vertical slopes with the constant total length of soil nails $32 \mathrm{~m}$. The three nail length Pattern s used for the analysis are presented in Figure 5.

From the simulation analysis, the factor of safety (FOS) corresponding to Pattern (1); Pattern (2); and Pattern (3) after the last excavation phase are $1.91 ; 1.71$ and 1.52 respectively. This result shows that using Pattern (3) would give the smallest deformation and this Pattern also provide the reasonable FOS $(>1.5)$.

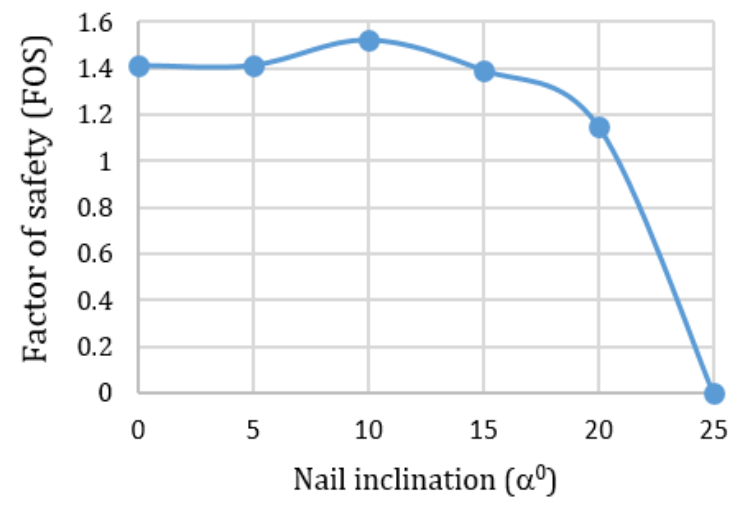

Figure 3. FoS distribution with changing soil nail inclination.

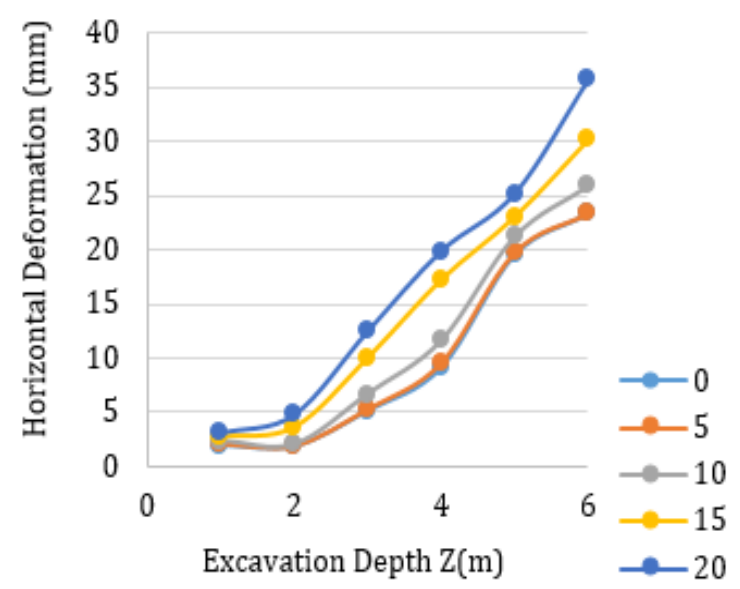

Figure 4. Relationship between horizontal deformation and soil nail inclination.

From Figure 5, the maximum horizontal displacement of slope after reinforcement is $U x=$ $25.92 * 10-3 \mathrm{~m}=2.6 \mathrm{~cm}$. With the maximum of excavation depth, the limit value of the horizontal displacement $\left[U_{x}\right]=H / 200=6 / 200=3 \mathrm{~cm}$. Owing to $U_{x}<\left[U_{x}\right]$ so that the Pattern 3 will be the most appropriate model, but in actual conditions of the work we need to consider the safety of construction.

The profiles of horizontal deformations of the excavation faces obtained from the analysis for the three nail length Pattern s are plotted in Table 4. Although nail length Pattern (1) has the highest FOS, its horizontal deformation is the largest, and this is followed by Pattern (2). Nail length Pattern (3), despite its lowest FOS, has the smallest deformation. Therefore, in a nailed excavation, installing longer nails at the top of the excavation will limit the amount of horizontal ground movement. 


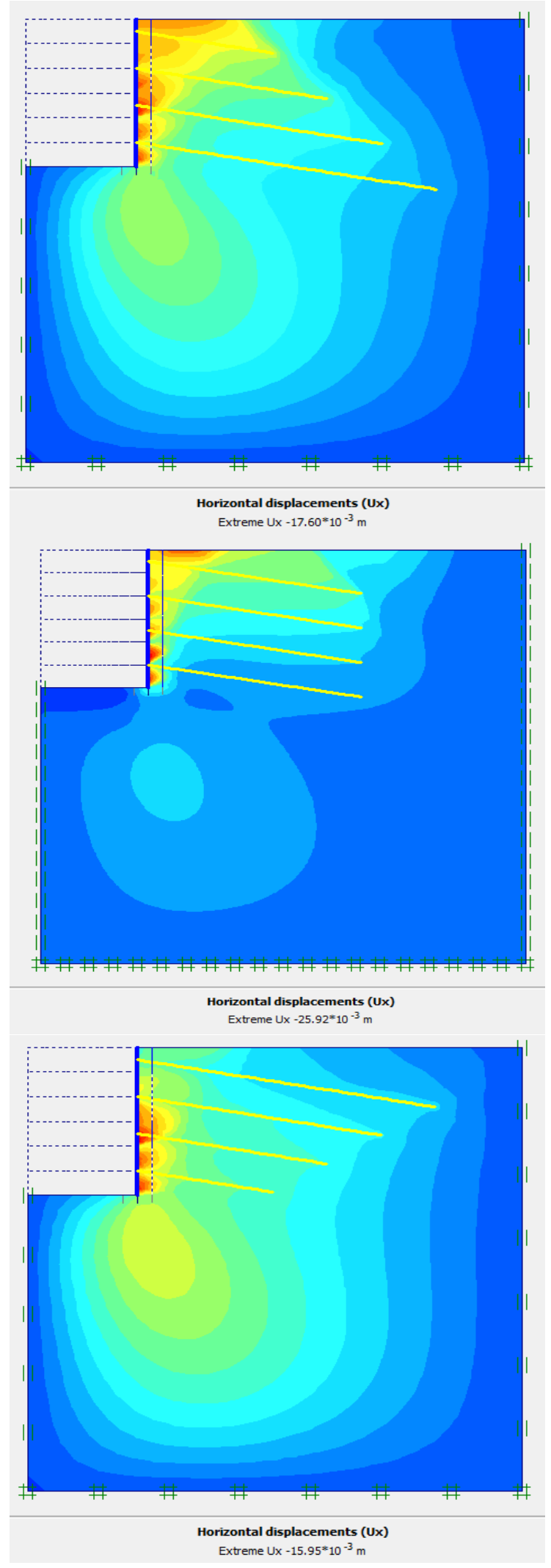

Figure 5. The maximum horizontal displacement of three nail length Patterns a) Pattern (1); b) Pattern (2); c) Pattern (3).
Table 4. Horizontal displacements of soil nail wall (Ux).

\begin{tabular}{|c|c|c|c|}
\hline \multirow{2}{*}{ Phase } & \multicolumn{3}{|c|}{ Horizontal displacements (Ux) mm } \\
\cline { 2 - 4 } & Pattern (1) & Pattern (2) & Pattern (3) \\
\hline 1 & 1.61 & 2.35 & 1.6 \\
\hline 2 & 3.69 & 2.02 & 3.72 \\
\hline 3 & 7.34 & 6.69 & 5.75 \\
\hline 4 & 12.34 & 11.62 & 11.18 \\
\hline 5 & 14.84 & 21.24 & 13.5 \\
\hline 6 & 17.60 & 25.92 & 15.95 \\
\hline
\end{tabular}

\section{Conclusions}

In the study, numerical simulations have been conducted to investigate the effects of soil nail inclination and length Pattern using the finite element method, applying the strength reduction technique. The method of study via a series of numerical analysis allows formulating the following conclusions:

1. The reinforcing action of the soil nails can be affected by the inclination of soil nails. Its inclination rising would make the reinforcing force in the nails decrease and reduce the stabilizing effect.

2. It can be seen that the horizontal deformation increases with increasing soil nail inclinations for this particular case study. The depth of excavation increases the displacement of soil nail wall increases, too. When $\alpha$ equals $25^{\circ}$, the FOS is close to 0 . This indicates that soil nails (modeled as geogrid) at such large inclinations do not provide any appreciable stabilizing effect.

3. The simulation results demonstrate that soil nails installed in the upper part are more efficient in the rising stability of soil - nailed slopes. Those placed in the lower part of a nailed structure in a staged - excavation contribute more toward reducing the horizontal displacement of soil - nailed slopes. It is due to their larger geogrid lengths beyond the potential failure surfaces.

\section{Author contributions}

Pham Thi Nhan: Conceived of the presented idea, wrote the manuscript; Pan Bing: Performed the analytic calculations and performed the numerical simulations; Nghia Viet Nguyen: Designed the model and analysed the data. 


\section{References}

Briaud, J. Land Lim, Y., (1997). Soil nailed wall under piled bridge abutment: simulation and guidelines. $J$ Geotech Geoenviron Eng 123(11):1043 - 1050.

Deepa, Vand Viswanadham, B. V. S., (2009). Centrifuge Model Tests on Soil - Nailed Slopes subjected to Seepage. Ground Improvement Journal, 162 (GI3), 133 - 144.

Dong Kim Hanh, (2015). Construction soil nailing for slope stabilization. Journal of water resources \& environmental engineering. ISSN 2207 - 5528 Vol. 48, P.P.85 - 91.

Fan, C. C and Luo, J. H., (2008). Numerical study on the optimum layout of soil nailed slopes. Comput Geotech 35(4):585 - 599.

FHWA, 1998. Manual for Design and Construction Monitoring of Soil Nail Wall. Federal Highway Administration, US Department of Transportation, USA.

Geotechnical Engineering Office, (2008). Guide to soil nail design and construction. Geoguide 7, Geotechnical Engineering Office, Hong Kong.

Ha Viet Nhu, Binh Van Duong, Hong Dang Vu, (2019). 3D slope stability modeling for landslide early warning design at Halong city area. Journal of Mining and Earth Sciences, Vol 60, Issue 6 (2019) 31 - 41.

Jewell, R. A. and Wroth, C. P., (1987). Direct shear tests on reinforced sand. Geotechnique, Vol. 37, No. 1, pp 53 - 68.

Jones, A. M. C. and Davies, M. C. R., (2000). An investigation of long term stability of soil nailed excavation using centrifuge modeling. Proceeding. 12WCEE, Auckland.

Lazarte, C. A., Robinson, H., Gómez, J. E., Baxter, A.,
Cadden A., and Berg, R., (2015). Soil Nail Walls Reference Manual No. FHWA - NH I - 14 - 007.

Moniuddin, M. D. K., Manjularani, P., and Govindaraju, L., (2016). Seismic analysis of soil nail performance in the deep excavation. International journal Geo - Engineering 7:16.

Nadher, H. and Baghdadi, Al, (2013). Stabilization of earth slopes by using soil nailing. Kufa Journal of Engineering (K.J.E) ISSN 2207 - 5528 Vol. 5, Issue 1, Dec, 2013, P.P.1 - 12.

Rotte, V. B. Viswanadham, Chourasia, D., (2013). Influence of slope geometry and nail parameters on the stability of soil - nailed slopes. International Journal of Geotechnical Engineering, ISSN: 1938 - 6362 (Print) 1939 7879.

Shiu, Y. K., and Chang, G. W. K., (2005). Effects of Inclination, Length Pattern and Bending Stiffness of Soil Nails on Behaviour of Nailed Structures. Geo Report No. 197, (Civil Engg. \& Development Dept.), Govt. of Hong Kong.

Singh, V. P. and Babu, G. L. S., (2009). 2D Numerical Simulations of Soil Nail Walls. Geotechnical and Geological Engineering 28(4):299 - 309 DOI: $10.1007 / \mathrm{s} 10706$ - 009 - 9292 - X

Tei, K., Taylor, R. N., and Milligan, G. W. E., (1998). Centrifuge Model Tests of Nailed Soil Slopes. Soils and Foundations, 38 (2), 165 - 177.

Zhang, J. P., Zhang, J. M., Qui, T., (2001). Model Tests by Centrifuge of Soil Nail Reinforcements. Journal of Testing and Evaluation, ASTM, 29 (4), 315 - 328.

Zhang, M., Song, E., Chen, Z., (1999). Ground Movement Analysis of Soil Nailing Construction By Three Dimensional (3 - D) Finite Element Modelling (FEM). Computers and Geotechnics, 25 (4), 191 - 204. 